\title{
Prediction of Base Shear for Three Dimensional RC Frame Subjected to Lateral Load using Artificial Neural Network
}

\author{
N. Jayaramappa*, A. Krishna, B. P. Annpurna and T. Kiran \\ Faculty of Engineering-Civil, UVCE, JBC, Bangalore University, Bangalore-560056, India; jakasauj@gmail.com
}

\begin{abstract}
The main objective of this paper is to predict the base shear for a three dimensional four storey single bay RC frame, subjected to lateral load, using Artificial Neural Network. Analytical Pushover analysis is carried out using ETAB software. Pushover curve is plotted for Base shear versus roof displacement, to the prototype model tested at Central Power Research Institute (CPRI) Bangalore. The analytical results obtained from ETAB analysis are compared with the results predicted from Artificial Neural Network (ANN). Displacement and plastic hinges are selected as input vectors to ANN. Back propagation algorithm has been used for training. A learning rate constant of 0.85 , error tolerance 0.001 , and 5500 cycles are used for training ANN. Delta rule is used for adjusting the weights. It is found that a four-layer network (5-6-6-1) which consists of 5 input neurons, two hidden layers of 6 neurons each and one output neuron efficiently converges almost close to analytical results with an error range of $0.17 \%$ to $8.25 \%$.
\end{abstract}

Keywords: ANN, Back Propagation, Base Shear, Delta Rule, Pushover

\section{Introduction}

Pushover analysis is a nonlinear static analysis, which is basically an inelastic static analysis, that gives due consideration to the material non-linearity, is an effective and efficient tool to evaluate the performance of the structure under lateral loads, especially seismic loads. The method not only provides information on strength capacity of structures but also provides vital information on ductility as well as an insight on the progressive mode of failure of the structure. Thus the method is more performancebased than conventional strength-based approach.

Artificial neural networks (ANN) ${ }^{1}$ have emerged as a computationally powerful tool in artificial intelligence with the potential of mapping an unknown nonlinear relationship between the given set of inputs and outputs. Their application can be widely seen in civil engineering field such as design, analysis, and optimization. The network consists of some layers of interconnected neurons.
In the computational model this is represented by an activation function of which includes a set of weights associated with each input value. The learning process is used to determine the proper weights. An Artificial Neural network composes of a number of interconnected units (artificial neurons). Each unit has an input/output characteristic and implements a local computation or function. The output of any unit is determined by its Input/Output characteristics, its interconnection to the other unit and external input, the network uses supervised learning using generalized delta rule.

\section{3D RC Frame Model}

The finite element package ETABS software (version-9.7.1; Fema-356) is used for the modeling and analysis of 3D RC frame. The building selected is a portion of a four storey office building assumed to be in seismic zone $\mathrm{IV}^{2}$. A brief summary of the building model is presented below.

${ }^{*}$ Author for correspondence 
Type of structure

: Ordinary moment resisting RC frame

Grade of concrete

: M 20

Grade of reinforcing steel

Plan size

: Fe 415

: $5 \mathrm{~m} \times 5 \mathrm{~m}$

Number of stories

Building height

Type of foundation

$: G+3$ storeys

: $12 \mathrm{~m}$ above ground storey

: Raft foundation which is supported on rock bed using rock grouting.

The building is an RC framed structure. The floor plan is same for all floors. The beam arrangement is different for the different roof. It is symmetric in both the direction. The concrete slab is $120 \mathrm{~mm}$ thick at each floor level. The details of plan and sectional elevation are shown in Figure 1.

\section{Methodology}

The following steps are involved in the pushover analysis.

Step 1: Create the basic computer 3D model using the graphical interface of ETABS and define the material properties, Geometric properties. The details of 3D model are shown in Figure 2.

Step 2: Assign all properties, boundary conditions and plastic hinges as per FEMA-356 to the analytical model.

Step 3: Define the pushover load cases. Typically the first pushover load case is used to apply gravity load and then subsequent lateral pushover load cases are specified.

Step 4: The beam-column joints are assumed to be rigid and are modeled by giving end-offsets to the frame elements. This was intended to get the bending moments at the face of the beams and columns. A rigid zone factor of 1 was considered to ensure rigid connections of the beams and columns.

Step 5: Define the analysis case. Nonlinear static pushover analysis, displacement controlled was defined for the present study.

Step 6: After assigning all properties to the model, the displacement controlled pushover analysis is carried out. The model is pushed in monotonic increasing order in a particular direction till the collapse of the structure.

Step 7: The base shear versus roof displacement curve (pushover curve) is obtained from the pushover analysis from which the maximum base shear capacity of structure can be obtained. The details of pushover curve for analytical results are shown in Graph 1.

Step 8: Figure 3 shows a layered feed-forward artificial neural network ${ }^{3}$. The circular nodes represent neurons.
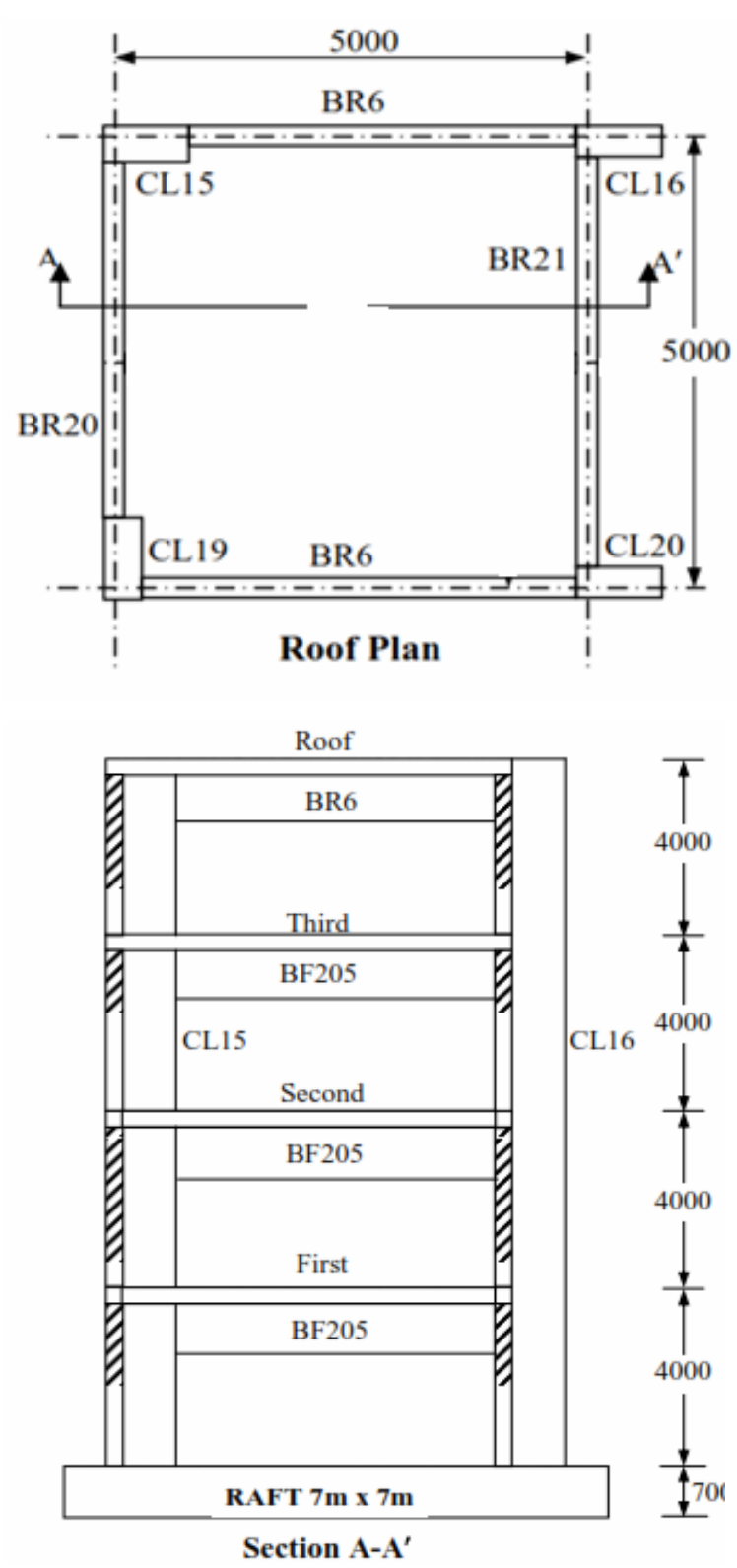

Figure 1. Geometry of the Model.

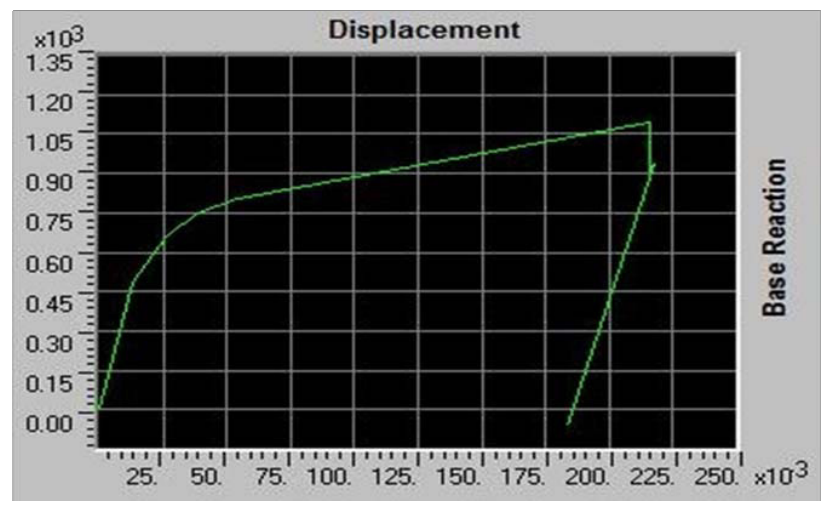

Graph 1. Pushover curve for four storey R.C. frame for experimental results. 


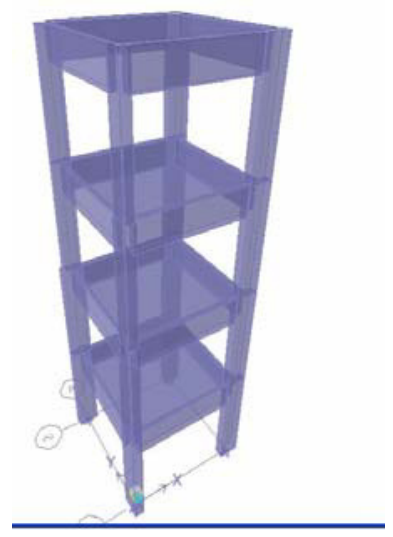

Figure 2. 3D Model for four storey R.C. frame.

Here there are four layers, an input layer, a two hidden layers and an output layer. The directed arrows are shows the connections from nodes of one layer to the nodes in other layers. A four-layer ANN (5-6-6-1) consists of 5 input neurons, two hidden layers of 6 neurons each and one output neuron, the details of ANN model is shown in Figure 3.

Step 9: Results obtained from analytical pushover analysis is taken as input values to ANN, The input data contains the normalized values of displacement and plastic hinges at different levels.

Step 10: Back propagation algorithm has been used for ANN training ${ }^{4}$. A learning rate constant of 0.85 , error tolerance 0.001 , and 5500 cycles are used for training. Delta rule is used for adjusting the weights. The network uses supervised learning using generalized delta rule 5 . For this learning, both a set of known deflection and corresponding base shear are made available. The learning algorithm in the form of generalized delta rules.

Initially the weights are randomly regenerated and as the iterations continue, the weights get modified to approximate values. After getting the expected output, store the weights, the details of weights generated from ANN are shown in Table 1. By using these weights, Base shear is predicted.The Table 2 shows the predicted Base Shear values.

Step 11: Obtain pushover curve for ETABS results and plot pushover curve to ANN predicted results, and then compared both the curves, the comparison is shown in Graph 3.

\section{Results}

The base shear for the roof displacement of four storey single bay 3D frame was found using ANN. Proposed

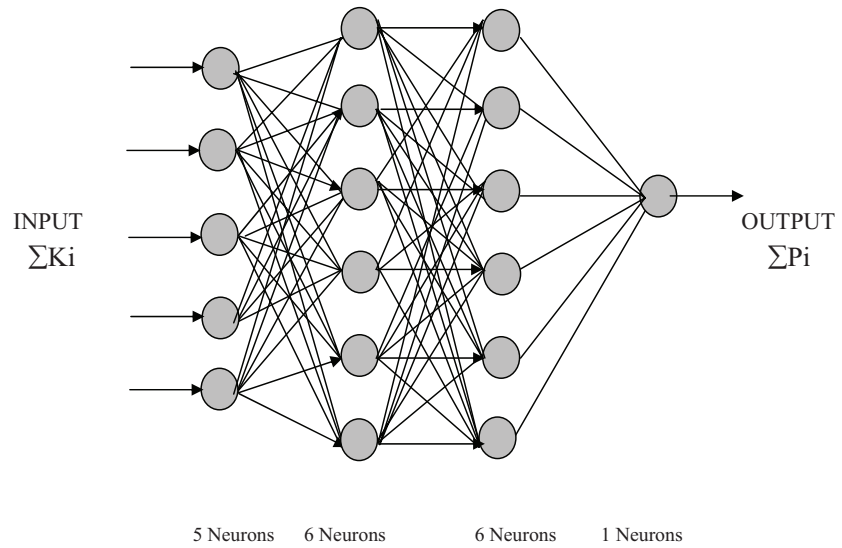

Figure 3. Artificial Neural Network-Model.

four-layer ANN is as shown in Figure 3. The input data contains the normalized values of displacement and plastic hinges. Back propagation algorithm has been used for training. A learning rate constant of 0.85 , error tolerance 0.001 , and 5500 cycles are used for training. Delta rule is used for adjusting the weights. The network uses supervised learning using generalized delta rule. For this learning, both a set of known deflection and corresponding base shear are made available. Initially the weights are randomly regenerated and as the iterations continue, the weights get modified to approximate values. About 26 input values of base shear values and associated deflection values were used while training the net.

The final weight assigned by ANN is shown in Table 1 . The Table 2 shows the results obtained from ETABS and ANN, last column of the Table 2 shows the percentage of error between ETABS results and ANN predicted values. Graph 2 and 3 shows the comparison of results with graphical representation.

\section{Recommendations}

In future, by using the weights assigned by ANN (Table 1), Bas shear for the other structures can be evaluated, so that it reduces the time required to evaluate base shear by computation.

\section{Conclusion}

A four-layered artificial neural network, effectively predicted base shear values almost close to that of values obtained from ETAB software. The Artificial neural network is trained for the above topology and conditions with back propagation algorithm taking displacement and 
Table 1. Weights assigned by Network

\begin{tabular}{|c|c|c|c|c|c|c|c|}
\hline \multirow[t]{2}{*}{ Layer - Layer } & \multicolumn{7}{|c|}{ Final weights assigned } \\
\hline & $1-1,2,3,4,5,6$ & 1.083712 & -0.013892 & -9.204333 & -0.997727 & 1.372978 & -3.831657 \\
\hline \multirow{4}{*}{$1-2$} & $2-1,2,3,4,5,6$ & -6.265245 & -4.894027 & -3.955773 & -4.263841 & 4.650630 & 4.965758 \\
\hline & $3-1,2,3,4,5,6$ & -0.274397 & 0.251388 & -2.726179 & -1.601955 & -4.594957 & -5.030927 \\
\hline & $4-1,2,3,4,5,6$ & -3.805275 & -1.803903 & 2.190382 & -0.977121 & -7.985647 & 2.876959 \\
\hline & $5-1,2,3,4,5,6$ & 2.945802 & 0.998845 & 4.262174 & -0.812646 & -8.088506 & -4.066069 \\
\hline \multirow{6}{*}{$2-3$} & $1-1,2,3,4,5,6$ & -0.458932 & -2.142061 & -2.752275 & 1.104134 & 6.477509 & -1.894662 \\
\hline & $2-1,2,3,4,5,6$ & -1.032982 & -1.524134 & -1.324592 & -0.155298 & 6.063562 & 0.130954 \\
\hline & $3-1,2,3,4,5,6$ & -0.441194 & 2.572973 & 7.440356 & -2.246905 & -0.375776 & -0.462194 \\
\hline & $4-1,2,3,4,5,6$ & -0.695111 & -1.993793 & -1.559198 & 0.554508 & 3.234217 & -1.128931 \\
\hline & $5-1,2,3,4,5,6$ & -1.326818 & 2.562415 & 2.848498 & -4.883502 & -7.413108 & 0.920785 \\
\hline & $6-1,2,3,4,5,6$ & -1.665605 & -4.923333 & -4.916848 & -4.097565 & -4.306969 & -3.978134 \\
\hline \multirow{6}{*}{$3-4$} & $3,1-4$ & -1.019986 & & & & & \\
\hline & $3,2-4$ & -4.510762 & & & & & \\
\hline & $3,3-4$ & -5.263477 & & & & & \\
\hline & $3,4-4$ & 2.158375 & & & & & \\
\hline & $3,5-4$ & 3.478460 & & & & & \\
\hline & $3,6-4$ & -2.648517 & & & & & \\
\hline
\end{tabular}

Table 2. Comparison of analytical results with ANN predicted results.

\begin{tabular}{|c|c|c|c|c|c|c|c|c|}
\hline \multicolumn{9}{|c|}{$(5-6-6-1,0.001,0.85,5500)$} \\
\hline Sl No & Displacement & LIS & IO & LS & Total (LIS+IO+LS) & $\begin{array}{l}\text { Base shear from } \\
\text { ETABS software }\end{array}$ & $\begin{array}{c}\text { ANN predicted } \\
\text { Base shear }\end{array}$ & $\%$ error \\
\hline 1 & 0.0100 & 0.143 & 0.01 & 0.00 & 0.144 & 0.2341548 & 0.254200 & 8.58 \\
\hline 2 & 0.0179 & 0.138 & 0.06 & 0.00 & 0.144 & 0.4201886 & 0.391000 & 6.95 \\
\hline 3 & 0.0200 & 0.131 & 0.13 & 0.00 & 0.144 & 0.4626744 & 0.486824 & 5.21 \\
\hline 4 & 0.0301 & 0.128 & 0.16 & 0.00 & 0.144 & 0.5431041 & 0.547796 & 0.86 \\
\hline 5 & 0.0426 & 0.128 & 0.16 & 0.00 & 0.144 & 0.6044199 & 0.594284 & 1.68 \\
\hline 6 & 0.0526 & 0.124 & 0.20 & 0.00 & 0.144 & 0.6452197 & 0.648817 & 0.55 \\
\hline 7 & 0.0625 & 0.121 & 0.22 & 0.01 & 0.144 & 0.6840802 & 0.688170 & 0.59 \\
\hline 8 & 0.0729 & 0.119 & 0.19 & 0.06 & 0.144 & 0.7073483 & 0.703899 & 0.34 \\
\hline 9 & 0.0852 & 0.117 & 0.13 & 0.14 & 0.144 & 0.7270923 & 0.708522 & 2.55 \\
\hline 10 & 0.1027 & 0.116 & 0.12 & 0.16 & 0.144 & 0.7533881 & 0.746150 & 0.96 \\
\hline 11 & 0.1219 & 0.114 & 0.14 & 0.15 & 0.144 & 0.7817883 & 0.789700 & 1.01 \\
\hline 12 & 0.1382 & 0.114 & 0.13 & 0.10 & 0.144 & 0.8050799 & 0.824214 & 2.37 \\
\hline 13 & 0.1482 & 0.113 & 0.13 & 0.09 & 0.144 & 0.8187427 & 0.835711 & 1.99 \\
\hline 14 & 0.1582 & 0.112 & 0.12 & 0.07 & 0.144 & 0.8324055 & 0.843537 & 1.33 \\
\hline 15 & 0.1682 & 0.111 & 0.12 & 0.07 & 0.144 & 0.8459657 & 0.851714 & 0.80 \\
\hline 16 & 0.1782 & 0.108 & 0.14 & 0.07 & 0.144 & 0.8593696 & 0.860890 & 0.17 \\
\hline 17 & 0.1934 & 0.106 & 0.16 & 0.07 & 0.144 & 0.8773875 & 0.870637 & 0.77 \\
\hline 18 & 0.2034 & 0.104 & 0.16 & 0.09 & 0.144 & 0.8886039 & 0.877824 & 1.21 \\
\hline 19 & 0.2211 & 0.104 & 0.16 & 0.09 & 0.144 & 0.9059449 & 0.884028 & 2.41 \\
\hline 20 & 0.2311 & 0.102 & 0.17 & 0.09 & 0.144 & 0.9154111 & 0.888301 & 2.96 \\
\hline 21 & 0.2452 & 0.102 & 0.17 & 0.09 & 0.144 & 0.9283922 & 0.891500 & 3.68 \\
\hline 22 & 0.2509 & 0.102 & 0.17 & 0.09 & 0.144 & 0.9335096 & 0.892575 & 4.39 \\
\hline 23 & 0.2510 & 0.102 & 0.17 & 0.09 & 0.144 & 0.8502250 & 0.892593 & 4.90 \\
\hline 24 & 0.2523 & 0.102 & 0.17 & 0.09 & 0.144 & 0.8649940 & 0.892821 & 3.20 \\
\hline 25 & 0.2558 & 0.102 & 0.17 & 0.09 & 0.144 & 0.8865629 & 0.892821 & 0.71 \\
\hline 26 & 0.2588 & 0.097 & 0.22 & 0.09 & 0.144 & 0.8954879 & 0.898028 & 0.28 \\
\hline
\end{tabular}




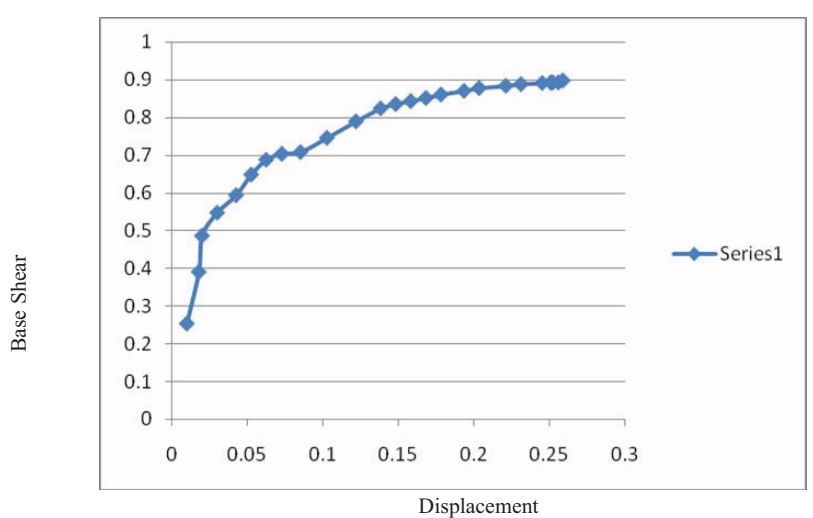

Series-1 Curve for results obtained from ETABS.

Graph 2. Pushover curve of four storey R.C. frame for ETAB results.

plastic hinges are input vector. The percentage difference/ error between the base shear from ETABS and the predicted values are within $8.85 \%$. The percentage of error can be still reduced by increasing input parameters.

\section{References}

1. Sharma A, Reddy GR. Report of Experimental Study conducted at CPRI. Bangalore: The behavior of real life four story one bay, RC frame, CPRI, Bangalore; 2010.

2. Rao VB, Rao HV. Neural networks \& fuzzy logic. New Delhi: BPB Publications; 1996.

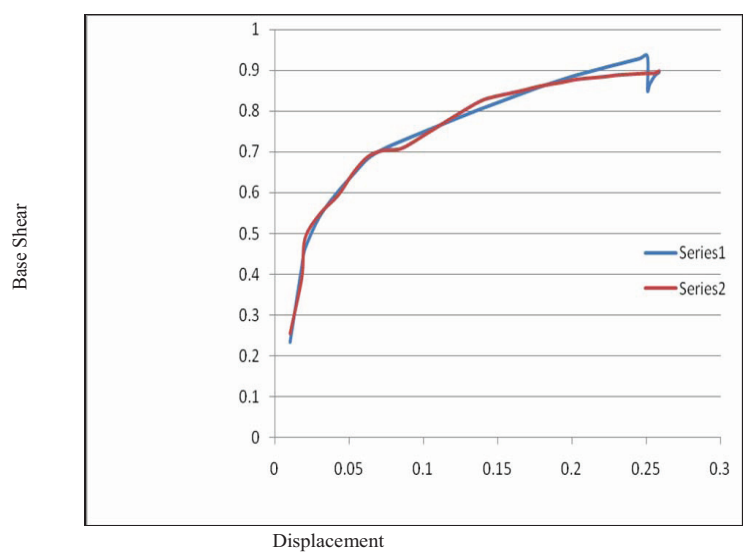

Series-1 Curve for results obtained from ETABS., Series-2 Curve for results obtained from ANN.

Graph 3. Pushover curve of four storey R.C. frame for ETAB results and $A N N$ results.

3. Jayaramappa N. Application of neural networks for prediction of buckling loads on columns. [M.E. thesis]. Bangalore: Bangalore University; 2001.

4. Swift RA, Batill SM. Application of neural networks to Preliminary design. 32nd SDM conference, AIAA. 1991. p. 335-43.

5. Vanluchene RE, Roufei S. Neural networks in structural engineering, Microcomputers in Civil Engineering. 1990; 5: 207-215.

6. Agarval P, Shrikhande M. Earthquake resistance design of structures. New Delhi: PHI Learning Private Limited; 2008. 